\title{
Interaction between Antihypertensive Therapy Class and Pulse Pressure on Outcomes Following Acute Ischemic Stroke
}

\author{
Michael Lavelle1, Roy 0. Mathew², Jaspreet Arora3 ${ }^{3}$ Avinash Murthy³, Le Du³, Batyrjan Bulibek ${ }^{3}$, \\ Mandeep Sidhu', Mikhail Torosoff ${ }^{4 *}$
}

\author{
${ }^{1}$ Department of Internal Medicine, Columbia University, New York Presbyterian Hospital, New York, NY, USA \\ ${ }^{2}$ Department of Medicine, William Jennings Bryan Dorn VA Medical Center, Columbia, SC, USA \\ ${ }^{3}$ Department of Internal Medicine, Albany Medical College, Albany, NY, USA \\ ${ }^{4}$ Division of Cardiology, Albany Medical Center, Albany, NY, USA \\ Email: *torosom@mail.amc.edu
}

How to cite this paper: Lavelle, M., Mathew, R.O., Arora, J., Murthy, A., Du, L., Bulibek, B., Sidhu, M. and Torosoff, M. (2017) Interaction between Antihypertensive Therapy Class and Pulse Pressure on Outcomes Following Acute Ischemic Stroke. International Journal of Clinical Medicine, 8, 543-555.

https://doi.org/10.4236/ijcm.2017.810051

Received: September 13, 2017

Accepted: October 14, 2017

Published: October 17, 2017

Copyright (c) 2017 by authors and Scientific Research Publishing Inc. This work is licensed under the Creative Commons Attribution International License (CC BY 4.0).

http://creativecommons.org/licenses/by/4.0/

\begin{abstract}
Goal: The effect of pulse pressure and interactions with type of antihypertensive therapy on mortality after acute ischemic stroke has not been previously evaluated. Materials and Methods: A retrospective cohort study was conducted to evaluate the independent and interactive effects of pulse pressure and antihypertensive class (specifically angiotensin converting enzyme inhibitor/angiotensin type 1 receptor blocker, or beta blocker) on mortality following acute ischemic stroke. Findings/Conclusions: 343 patients were identified with 49 months of follow-up. Baseline pulse pressure was $64 \mathrm{mmHg}$ and age was 66.5 years. Patients were divided at a pulse pressure of 70 . Patients with pulse pressure $\geq 70$ were older $(p<0.001)$ and had higher comorbid vascular burden $(\mathrm{p}=0.031)$ than those with pulse pressure $<70$. Pulse pressure did not remain a significant predictor of follow-up mortality after adjustment for baseline comorbidities. Angiotensin converting enzyme inhibitor/angiotensin type 1 receptor blocker based therapy was associated with lower follow-up mortality when beta blocker was not used in pulse pressure $<70$ group (odds ratio $0.07,95 \%$ confidence interval $0.01-0.48$ ). Prospective analysis will be needed to confirm the protective effect of angiotensin converting enzyme inhibitor/angiotensin type 1 receptor blocker based on pulse pressure in acute ischemic stroke.
\end{abstract}

\section{Keywords}

Acute Ischemic Stroke, Pulse Pressure, Angiotensin Blockers, Beta Blockers, Outcomes 


\section{Introduction}

The relationship between blood pressure (BP) control and short and long term outcomes in patients with acute ischemic stroke (AIS) is highly complex and not well understood with conflicting data. More than half of ischemic stroke patients had systolic blood pressure (SBP) above $160 \mathrm{mmHg}$ within the first 48 hours of symptom onset in the International Stroke Trial (IST) [1]. However, the IST evaluation demonstrated a U-shaped relationship between SBP at both 14-day and 6 month outcomes. The most interesting was an increased risk of death at 14 days by $17.9 \%$ for every $10 \mathrm{mmHg}$ SBP less than $150 \mathrm{mmHg}$ compared to a $3.8 \%$ increased risk of death with each $10 \mathrm{mmHg}$ increase above $150 \mathrm{mmHg}$ (3.6\% vs. $1.1 \%$ for 6 month death or dependency) [1]. On the other hand, recurrent AIS within 14-days was directly associated with increased SBP, which independently predicted the likelihood of AIS in a multivariate analysis [1].

Currently, the evidence does not support aggressive management of BP during AIS as a global strategy [2]. Although significantly elevated BP in AIS is deleterious, rapid reduction of SBP has been associated with a higher mortality [3] with cerebral hypoperfusion and increased cardiac events [4]. Reducing diastolic BP (DBP) by $>20 \%$ also significantly increases the risk of death [5]. Citing conflicting evidence, the 2013 ACC/AHA Guidelines for the "Early Management of Patients with Acute Ischemic Stroke" did not specify BP targets and suggest using "best clinical judgment" and "to initially lower the SBP by $15 \%$ and monitor for neurological deterioration related to the (blood) pressure lowering" [2].

An important component of BP is the difference between SBP and DBP, or the pulse pressure (PP) [6]. Increased PP above a population norm has been associated with inferior outcomes in AIS [7] [8] [9] [10] [11], especially when PP exceeds $70 \mathrm{mmHg}$ [7]. With the varying components of BP and the diversity of findings among the clinical trials of BP in AIS, the optimal approach to BP management in AIS remains unclear. Likewise, the choice of antihypertensive treatment in AIS and during follow-up has not been well established [12]. Angiotensin converting enzyme inhibitors (ACEI) were demonstrated to prevent recurrent strokes [13] and improve hospital [14] and follow-up survival [15]. Some studies suggested benefit with angiotensin II receptor blocker (ARB) [16] [17] [18] [19]; while calcium channel blocker (CCB) [5] [20] and beta-adrenergic blocker (BB) [21] [22] [23] therapies failed to show consistent reduction in mortality and prevention of recurrent stroke.

The effects of anti-hypertensive therapy on outcomes in patients with AIS and widened pulse pressure (WPP) have not been well studied previously. In this observational study, we examined whether treatment of hypertension modulates adverse effects of WPP in ischemic stroke. We have chosen to define WPP as a value of $\geq 70 \mathrm{mmHg}$ as this cut point has been shown to be associated with poorer outcomes in previous studies [7]. 


\section{Methods}

\subsection{Study Design and Patient/Variable Selection}

Retrospective chart review was performed and follow-up outcomes (49.7 \pm 22.4 months) were ascertained in 343 consecutive patients treated for AIS at a single tertiary care academic medical center, certified as Primary Stroke Center [24]. Patients were identified utilizing a hospital billing database, according to the discharge diagnosis code (ICD9 for acute stroke-434.xx, 435.xx, or 436.xx-in addition patients needed to have had an echocardiogram that was ordered to look for an embolic source).

The hospital's diagnostic evaluation and therapeutic interventions followed the 2003 "Guideline for The Management of Patients with Ischemic Stroke" [25]. Quality of care was ascertained according to the "Get With The Guidelines" [26] program criteria. During the study time period (2008 to 2011), the treating hospital was recognized for the performance achievement, with more than $85 \%$ of patients having received care according to the guideline, attesting to the quality and consistency of the care provided. Initial BP measurements were performed by properly trained Emergency Department triage $\mathrm{RN}$ in the supine patient, employing automated BP measurement unit with an appropriate size cuff for the patient's habitus. The discharge criterion for hypertension management was attaining BP of $<140 / 90 \mathrm{mmHg}$, unless it could not be tolerated; this is consistent with the current "Evidence-Based Guideline for the Management of High BP in Adults: Report from the Panel Members Appointed to the Eighth Joint National Committee (JNC 8)" [27].

The choice of employed anti-hypertensive medications was determined by patient co-morbidities and the intensity of each required therapy. Treatment followed recommendation of "The Seventh Report of the Joint National Committee on Prevention, Detection, Evaluation, and Treatment of High Blood Pressure" [28]. All medications were titrated to the maximal safe dosing to ensure goal BP management.

Outcomes were assessed until 2015 and were classified as in-hospital mortality in patients who expired during index admission, follow-up mortality in patients who expired during the follow-up period, and survivors. Outcomes and causes of death were determined through hospital charts and death certificates, and status was verified through the Social Security Death Index database [29] [30]. The study was approved by the institutional IRB at the Albany Medical College.

\subsection{Statistical Analysis}

Continuous variables were expressed as means and standard deviations. Differences in continuous variables were assessed with an unpaired t-test and non-parametric Kruskall-Wallis test, when appropriate. Categorical data was expressed as proportions and the differences in proportions were assessed with Chi-square analysis and Fisher's exact test, when appropriate.

Univariate logistic regression analysis was used to identify predictors of short 
and follow-up mortality. Statistically significant univariable predictors of acute and follow-up mortality were subsequently entered in a multivariable logistic regression model to adjust for other risk factors. The dependent variables were hospital and follow up mortality and the independent variables were age, peripheral vascular disease, end-stage renal failure, Glasgow coma scale, $\mathrm{PP} \geq 70 \mathrm{mmHg}$, and antihypertensive therapy utilized. An additional multivariable logistic regression was performed with ACEI or ARB therapy and Beta Blocker therapy as the dependent variables. The independent variables were sex, age, CAD, hypertension, diabetes, hyperlipidemia, peripheral arterial disease (PAD), end-stage renal disease, $\mathrm{PP} \geq 70 \mathrm{mmHg}$, type of stroke and Glasgow coma scale. No data points were discarded; all patients alive at end of follow-up period were censored for long term outcomes assessment. For multivariable analysis, patients with missing data for the analysis were excluded.

$\mathrm{P}$-value of $<0.05$ was used to indicate statistical significance and all p-values were two-tailed. All analyses were conducted with commercially available statistical software (JMP 7.0.2, SAS, NC, 2007).

\section{Results}

After inclusion and exclusion criteria were applied a total of 322 patients were identified for the study cohort (Table 1 ). The population was $43.8 \%$ female and the average age was 66.5 years. Table 1 also contains baseline demographic parameters for the cohort with baseline pulse pressure (PP) $\geq$ and $<70$. Patients with a $\mathrm{PP} \geq 70$ were older than those with $\mathrm{PP}<70$ (73.7 vs. 62.8 years, $\mathrm{p}<0.001)$. Patients with $\mathrm{PP} \geq 70$ were more likely to have a history of hypertension ( $83.5 \mathrm{vs}$. $68.1 \%, \mathrm{p}=0.003)$, and PAD (67\% vs. $54.6 \%, \mathrm{p}=0.031)$. The difference in $\mathrm{PP}$ between the two groups was driven by SBP. The first recorded SBP was 175.5 in patients with $\mathrm{PP} \geq 70$ and 133.7 in $\mathrm{PP}<70$ ( $\mathrm{p}<0.001)$; there was no difference between groups in first recorded DBP. The first recorded PP (in $\mathrm{mmHg}$ ) was 49.8 and 89.6 in patients with $\mathrm{PP}<70$ and $\geq 70$, respectively $(\mathrm{p}<0.001)$. Patients with $\mathrm{PP} \geq 70$ were more likely to be placed on an ACEI/ARB or BB as compared to those with $\mathrm{PP}<70$ (53.9 vs. 31.9\%, $\mathrm{p}<0.001$ ). Patients with $\mathrm{PP} \geq 70$ were less likely to be on monotherapy with $\mathrm{BB}$ therapy or not treated with $\mathrm{BB}$ at all.

Regarding the choice of antihypertensive class-ACEI/ARB or BB-patients in either of these two classes were similar in baseline comorbidity profile except for having a history of coronary artery disease without prior revascularization, which was more common in BB group (Table 2).

\section{Outcomes}

Overall in-hospital mortality was 5.3\%. The average length of follow-up data was 49.7 months. Mortality during follow up for the overall cohort was $28.2 \%$ (Table 1). There was no difference between PP groups for in-hospital mortality. Follow-up mortality was significantly higher among those with a baseline PP > 70 (37.4 vs. $23.2 \%, \mathrm{p}=0.009$ ) (Table 1 ). On univariate analysis, older age, the 
Table 1. Demographic data and clinical parameters.

\begin{tabular}{|c|c|c|c|c|}
\hline Parameter & $\begin{array}{l}\text { Any PP } \\
\mathrm{N}=322\end{array}$ & $\begin{array}{c}\mathrm{PP}<70 \mathrm{mmHg} \\
\mathrm{N}=207\end{array}$ & $\begin{array}{c}\mathrm{PP} \geq 70 \mathrm{mmHg} \\
\mathrm{N}=115\end{array}$ & $\begin{array}{c}\text { Between group } \\
\text { p-value }\end{array}$ \\
\hline Females: $\mathrm{n}(\%)$ & $141(43.8)$ & $88(42.5)$ & $53(46.1)$ & 0.536 \\
\hline Age, years: mean \pm SD & $66.5 \pm 15.6$ & $62.8 \pm 15$ & $73.7 \pm 13.4$ & $<0.001$ \\
\hline Age $<50$ years old: $\mathrm{n}(\%)$ & $42(13)$ & $37(17.9)$ & $5(4.3)$ & \\
\hline Age 50 - 69 years old: $n(\%)$ & $134(41.6)$ & 97 (46.9) & $37(32.2)$ & $<0.001$ \\
\hline Age 70 years or older: $\mathrm{n}(\%)$ & $146(45.3)$ & $73(35.3)$ & $73(63.5)$ & \\
\hline History of CAD: $n(\%)$ & $81(25.2)$ & $46(22.2)$ & $35(30.4)$ & 0.104 \\
\hline No CAD history & $241(74.8)$ & $161(77.8)$ & $80(69.6)$ & \multirow{4}{*}{0.110} \\
\hline CAD w/o revascularization & $41(12.7)$ & $27(13)$ & $14(12.2)$ & \\
\hline CAD with CABG history & $21(6.5)$ & $9(4.3)$ & $12(10.4)$ & \\
\hline CAD with PCI history & $19(5.9)$ & $10(4.8)$ & $9(7.8)$ & \\
\hline History of hypertension: $\mathrm{n}(\%)$ & $237(73.6)$ & $141(68.1)$ & $96(83.5)$ & 0.003 \\
\hline History of diabetes: $\mathrm{n}(\%)$ & $94(29.2)$ & $60(29)$ & $34(29.6)$ & 0.913 \\
\hline History of dyslipidemia: $\mathrm{n}(\%)$ & $183(56.8)$ & $113(54.6)$ & $70(60.9)$ & 0.276 \\
\hline History of peripheral vascular disease: $\mathrm{n}(\%)$ & $190(59)$ & $113(54.6)$ & $77(67)$ & 0.031 \\
\hline Creatinine $>2 \mathrm{mg} / \mathrm{dL}$ or HD: $\mathrm{n}(\%)$ & $15(4.7)$ & $8(3.9)$ & $7(6.1)$ & 0.365 \\
\hline First recorded SBP, mmHg: mean \pm SD & $148.6 \pm 29.7$ & $133.7 \pm 20.6$ & $175.5 \pm 24$ & $<0.001$ \\
\hline First recorded DBP, mmHg: mean \pm SD & $84.6 \pm 17.2$ & $83.9 \pm 16.2$ & $85.9 \pm 18.8$ & 0.331 \\
\hline First recorded pulse pressure, $\mathrm{mmHg}$ : mean $\pm \mathrm{SD}$ & $64 \pm 23$ & $49.85 \pm 12$ & $89.65 \pm 14$ & $<0.001$ \\
\hline Pulse pressure $\geq 70$ mmHg: $\mathrm{n}(\%)$ & $115(35.7)$ & & & \\
\hline \multicolumn{5}{|l|}{ Type of stroke: n (\%) } \\
\hline Embolic & $191(59.3)$ & $120(58)$ & $71(61.7)$ & \multirow{3}{*}{0.051} \\
\hline Lacunar & $39(12.1)$ & $20(9.7)$ & $19(16.5)$ & \\
\hline Transient ischemic attack & $92(28.6)$ & $67(32.4)$ & $25(21.7)$ & \\
\hline Admission Glasgow coma scale, units: mean \pm SD & $13.6 \pm 1.9$ & $13.7 \pm 1.7$ & $13.4 \pm 2$ & 0.173 \\
\hline Beta-Blockers: n (\%) & $174(54)$ & $100(48.3)$ & $74(64.3)$ & 0.005 \\
\hline ACEI or ARB: $\mathrm{n}(\%)$ & $206(64)$ & $116(56)$ & $90(78.3)$ & $<0.001$ \\
\hline ACEI or ARB with beta-blocker & $128(39.8)$ & $66(31.9)$ & $62(53.9)$ & \multirow{4}{*}{$<0.001$} \\
\hline Beta-blocker without ACEI or ARB & $46(14.3)$ & $34(16.4)$ & $12(10.4)$ & \\
\hline ACEI or ARB without beta-blocker & $78(24.2)$ & $50(24.2)$ & $28(24.3)$ & \\
\hline No ACEI or ARB, no beta-blocker & $70(21.7)$ & $57(27.5)$ & $13(11.3)$ & \\
\hline Diuretics: n (\%) & $33(10.2)$ & $20(9.7)$ & $13(11.3)$ & 0.642 \\
\hline Other anti-HTN Rx: n (\%) & $9(2.8)$ & $3(1.5)$ & $6(5.2)$ & 0.145 \\
\hline Interval to target blood pressure, days: mean $\pm \mathrm{SD}$ & $5.5 \pm 8.4$ & $1.7 \pm 1.2$ & $7.8 \pm 10.2$ & 0.355 \\
\hline In-hospital mortality: $\mathrm{n}(\%)$ & $17 / 322(5.3)$ & $9(4.3)$ & $8(7)$ & 0.316 \\
\hline Follow-up length, months: mean \pm SD & $49.7 \pm 22.4$ & $51.4 \pm 21.9$ & $47 \pm 22.7$ & 0.092 \\
\hline Follow-up mortality: $\mathrm{n}(\%)$ & $86 / 305(28.2)$ & $46 / 198(23.2)$ & $40 / 107(37.4)$ & 0.009 \\
\hline
\end{tabular}

Abbreviations: SD—standard deviation; SBP—systolic blood pressure; DBP—diastolic blood pressure; BB—beta-adrenergic blockers; ACEI—angiotensin converting enzyme inhibitors; $\mathrm{ARB}$ - angiotensin receptor blockers; IV—intravenous; HTN_hypertension; Rx-therapy. 
Table 2. Demographic and clinical parameters associated with anti-hypertensive medication utilization.

\begin{tabular}{|c|c|c|c|c|}
\hline \multirow{2}{*}{ Parameter } & \multicolumn{2}{|c|}{ ACEI or ARB $(\mathrm{N}=215)$} & \multicolumn{2}{|c|}{ Beta-Blocker $(\mathrm{N}=80)$} \\
\hline & OR $(95 \% \mathrm{CI})$ & $\mathrm{p}$-value & OR $(95 \% \mathrm{CI})$ & p-value \\
\hline Male gender & $1.416(0.912-2.199)$ & 0.122 & $1.413(0.921-2.167)$ & 0.113 \\
\hline Age, per 10 years & $1.337(1.155-1.548)$ & 0.001 & $1.507(1.294-1.755)$ & $<0.001$ \\
\hline CAD (any) & $2.340(1.388-4.092)$ & 0.003 & $3.451(2.003-5.945)$ & $<0.001$ \\
\hline $\mathrm{CAD}$ w/o revascularization & $1.543(0.781-3.048)$ & 0.212 & $3.615(1.751-7.466)$ & $<0.001$ \\
\hline CAD—CABG history & $3.060(1.001-9.351)$ & 0.049 & $3.013(1.133-8.012)$ & 0.027 \\
\hline CAD_PCI history & $6.480(1.472-28.518)$ & 0.013 & $3.615(1.276-10.244)$ & 0.016 \\
\hline Hypertension & $11.080(6.352-19.327)$ & $<0.001$ & $3.886(2.335-6.467)$ & $<0.001$ \\
\hline Diabetes & $2.901(1.683-4.999)$ & $<0.001$ & $1.789(1.109-2.887)$ & 0.017 \\
\hline Dyslipidemia & $3.301(2.092-5.209)$ & $<0.001$ & $1.706(1.108-2.627)$ & 0.015 \\
\hline Peripheral vascular disease & $2.580(1.644-4.048)$ & $<0.001$ & $2.076(1.341-3.215)$ & 0.001 \\
\hline Creatinine $>2 \mathrm{mg} / \mathrm{dL}$ or $\mathrm{HD}$ & $1.995(0.636-6.256)$ & 0.236 & $1.703(0.615-4.715)$ & 0.305 \\
\hline Pulse pressure $\geq 70 \mathrm{mmHg}$ & $2.824(1.677-4.756)$ & $<0.001$ & $1.931(1.208-3.087)$ & 0.006 \\
\hline Lacunar vs. embolic stroke & $1.325(0.649-2.703)$ & 0.439 & $0.871(0.537-1.413)$ & 0.575 \\
\hline TIA vs. embolic stroke & $0.883(0.538-1.449)$ & 0.623 & $1.185(0.606-2.317)$ & 0.619 \\
\hline Glasgow coma scale & $1.004(0.894-1.128)$ & 0.941 & $0.952(0.850-1.067)$ & 0.401 \\
\hline
\end{tabular}

Abbreviations: $\mathrm{OR}$-odds ratio; $\mathrm{ACEI}$ - angiotensin converting enzyme inhibitors; $\mathrm{ARB}$ — angiotensin receptor blockers; CAD—coronary artery disease; CABG - coronary artery bypass graft surgery; PCI-percutaneous coronary intervention; TIA—transient ischemia attack.

presence of $\mathrm{CAD}$ without prior revascularization, presence of $\mathrm{PAD}$, having a creatinine $>2 \mathrm{mg} / \mathrm{dl}$ or being on hemodialysis, having a Glasgow Coma Scale score $>9$, $\mathrm{PP}>70$, requiring intravenous anti-hypertensive therapy during the hospitalization, and being on a BB based anti-hypertensive regimen were all significantly associated with increased follow-up mortality. In-hospital mortality was non-significantly lower for patients treated with ACEI/ARB compared to those not treated with ACEI/ARB (3.7\% vs. 8.6\%); follow up mortality was similar between the anti-hypertensive therapy groups $(27.4 \%$ vs. $24.2 \%, \mathrm{p}=0.150)$. Looking at various combinations of ACEI/ARB and BB based therapy, being on an ACEI/ARB based therapy without BB was associated with lowest in-hospital and follow up mortality $(2.5 \%$ and $16 \%$, respectively, $\mathrm{p}=0.003)$ (Table 3 ).

After adjustment for covariates in multivariate analysis (Table 4), PP > 70 was not independently associated with an elevated odds ratio (OR) of in-hospital or follow-up mortality. However, choice of antihypertensive therapy remained important in determining outcomes; there were also some subtle differences in the effects of antihypertensive therapy choice based on baseline PP. Being on an ACEI or ARB based antihypertensive regimen was associated with a lower probability of in-hospital mortality in both PP groups. When BB therapy was included in antihypertensive therapy with ACEI/ARB, the lowering of in-hospital mortality was attenuated in the $\mathrm{PP}>70$ group, but not in the $\mathrm{PP}<70$ group. Follow-up 
Table 3. Effects of clinical parameters, pulse pressure, and anti-hypertensive medications on mortality.

\begin{tabular}{|c|c|c|c|c|c|}
\hline \multirow[b]{2}{*}{ Parameter } & \multirow[b]{2}{*}{ Category } & \multirow[b]{2}{*}{$\mathrm{N}$} & \multicolumn{3}{|c|}{ Mortality: n (\%) } \\
\hline & & & $\begin{array}{c}\text { In-Hospital } \\
\mathrm{N}=19\end{array}$ & $\begin{array}{c}\text { Follow-Up } \\
\mathrm{N}=90\end{array}$ & p-value \\
\hline \multirow{2}{*}{ Gender } & Females & 153 & $6(3.9)$ & $38(24.8)$ & \multirow{2}{*}{0.390} \\
\hline & Males & 190 & $13(6.8)$ & $52(27.4)$ & \\
\hline \multirow{3}{*}{ Age group, years } & $<50$ & 47 & $0(0)$ & $1(2.1)$ & \multirow{3}{*}{$<0.001$} \\
\hline & $50-69$ & 141 & $7(5)$ & $22(15.6)$ & \\
\hline & $>70$ & 155 & $12(7.7)$ & $67(43.2)$ & \\
\hline \multirow{2}{*}{ CAD } & Yes & 85 & $8(9.4)$ & $27(31.8)$ & \multirow{2}{*}{0.054} \\
\hline & No & 258 & $11(4.3)$ & $63(24.4)$ & \\
\hline \multirow{4}{*}{ CAD with revascularization history } & CAD-no CABG-PCI & 44 & $5(11.4)$ & $22(50)$ & \multirow{4}{*}{$<0.001$} \\
\hline & CAD-CABG & 21 & $2(9.5)$ & $3(14.3)$ & \\
\hline & CAD-PCI & 20 & $1(5)$ & $2(10)$ & \\
\hline & No CAD & 258 & $11(4.3)$ & $63(24.4)$ & \\
\hline \multirow{2}{*}{ Hypertension } & Yes & 247 & $16(6.5)$ & $68(27.5)$ & \multirow{2}{*}{0.272} \\
\hline & No & 96 & $3(3.1)$ & $22(22.9)$ & \\
\hline \multirow{2}{*}{ Diabetes } & Yes & 99 & $3(3)$ & $30(30.3)$ & \multirow{2}{*}{0.286} \\
\hline & No & 244 & $16(6.6)$ & $60(24.6)$ & \\
\hline \multirow{2}{*}{ Dyslipidemia } & Yes & 196 & $10(5.1)$ & $56(28.6)$ & \multirow{2}{*}{0.510} \\
\hline & No & 147 & $9(6.1)$ & $34(23.1)$ & \\
\hline \multirow{2}{*}{ Peripheral vascular disease } & Yes & 202 & $17(8.4)$ & $64(31.7)$ & \multirow{2}{*}{$<0.001$} \\
\hline & No & 141 & $2(1.4)$ & $26(18.4)$ & \\
\hline \multirow{2}{*}{$\mathrm{Cr}>2.0 \mathrm{mg} / \mathrm{dL}$ or $\mathrm{HD}$} & Yes & 17 & $0(0)$ & $12(70.6)$ & \multirow{2}{*}{$<0.001$} \\
\hline & No & 326 & $19(5.8)$ & $78(23.9)$ & \\
\hline & $<9$ & 301 & $2(0.7)$ & $77(25.6)$ & \\
\hline Glasgow coma scale & $9-12$ & 30 & $6(20)$ & $12(40)$ & $<0.001$ \\
\hline \multirow{3}{*}{ Pulse pressure group (mmHg) } & $>12$ & 12 & $11(91.7)$ & $1(8.3)$ & \\
\hline & $\geq 70$ & 115 & $8(7)$ & $40(34.8)$ & \multirow{2}{*}{0.020} \\
\hline & $<70$ & 207 & $9(4.3)$ & $46(22.2)$ & \\
\hline \multirow{2}{*}{ IV anti-HTN Rx } & Yes & 49 & $3(6.1)$ & $20(40.8)$ & 0037 \\
\hline & No & 294 & $16(5.4)$ & $70(23.8)$ & 0.037 \\
\hline $\mathrm{ACFI}$ or $\mathrm{ARBc}$ & Yes & 215 & $8(3.7)$ & $59(27.4)$ & 0150 \\
\hline ACEI OI AKDS & No & 128 & $11(8.6)$ & $31(24.2)$ & 0.130 \\
\hline & Yes & 180 & $9(5)$ & $61(33.9)$ & \\
\hline Beta-blockers & No & 163 & $10(6.1)$ & $29(17.8)$ & 0.003 \\
\hline ACEI or ARB and beta-blocker group & & & & & \\
\hline ACEI or ARB and beta-blocker & & 134 & $6(4.5)$ & $46(34.3)$ & \\
\hline ACEI or ARB without beta-blocker & & 81 & $2(2.5)$ & $13(16)$ & 0011 \\
\hline Beta-blocker without ACEI or ARB & & 46 & $3(6.5)$ & $15(32.6)$ & 0.011 \\
\hline No ACEI or ARB or beta-blocker & & 82 & $8(9.8)$ & $16(19.5)$ & \\
\hline Diuretics & Yes & 36 & $2(10.5)$ & $7(19.4)$ & 0.613 \\
\hline Ditaretics & No & 307 & $17(5.5)$ & $83(27)$ & 0.010 \\
\hline Othor anti HTN D & Yes & 10 & $0(0)$ & $3(30)$ & 0057 \\
\hline 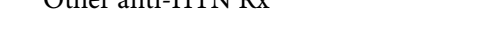 & No & 333 & $19(6.5)$ & $87(26.1)$ & 0.907 \\
\hline
\end{tabular}

Abbreviations: CAD—coronary artery disease; HTN-hypertension; Rx - therapy; IV—intravenous; ACEI-angiotensin converting enzyme inhibitor; $\mathrm{ARB}$-angiotensin receptor blockers. 
Table 4. Multivariate predictors of hospital and follow-up mortality.

\begin{tabular}{|c|c|c|c|c|}
\hline \multirow{2}{*}{ Parameter } & \multicolumn{2}{|l|}{ Hospital mortality } & \multicolumn{2}{|c|}{ Follow-up mortality } \\
\hline & OR $(95 \% \mathrm{CI})$ & p-value & OR $(95 \% \mathrm{CI})$ & p-value \\
\hline Age, per 10 years & $1.140(0.536-2.427)$ & 0.734 & $2.244(1.713-2.939)$ & $<0.001$ \\
\hline CAD-no revascularization ${ }^{*}$ & $1.157(0.114-11.732)$ & 0.902 & $2.81(1.179-6.699)$ & 0.019 \\
\hline CAD-CABG ${ }^{*}$ & $2.570(0.067-99.294)$ & 0.613 & $0.328(0.081-1.333)$ & 1.119 \\
\hline $\mathrm{CAD}-\mathrm{PCI}^{*}$ & $1.028(0.005-212.635)$ & 0.992 & $0.207(0.039-1.115)$ & 0.067 \\
\hline Peripheral vascular disease & $7.217(0.816-63.849)$ & 0.0756 & $1.584(0.801-3.131)$ & 0.186 \\
\hline $\mathrm{Cr}>2 \mathrm{mg} / \mathrm{dL}$ or $\mathrm{HD}$ & Insufficient cases & & $7.34(1.885-28.573)$ & 0.004 \\
\hline Glasgow coma scale $9-12 \dagger$ & $33.809(4.973-229.843)$ & $<0.001$ & $2.748(0.948-7.967)$ & 0.063 \\
\hline Glasgow coma scale $>12 \dagger$ & $3544.895(150.124-83705.887)$ & $<0.001$ & \multicolumn{2}{|c|}{ Insufficient cases } \\
\hline Pulse pressure $\geq 70 \mathrm{mmHg}$ & $1.829(0.239-13.985)$ & 0.561 & $1.07(0.533-2.149)$ & 0.849 \\
\hline IV anti-HTN Rx & $0.325(0.008-13)$ & 0.325 & $1.685(0.693-4.095)$ & 0.249 \\
\hline ACEI or ARB with $\mathrm{BB}+\dagger$ & $0.078(0.006-0.972)$ & 0.078 & $0.652(0.253-1.679)$ & 0.375 \\
\hline $\mathrm{ACEI}$ or $\mathrm{ARB}$ w/o $\mathrm{BB} \dagger \dagger$ & $0.024(0.001-0.763)$ & 0.035 & $0.363(0.129-1.019)$ & 0.054 \\
\hline $\mathrm{BB}$ w/o ACEI or ARB $\dagger \dagger$ & $0.105(0.006-1.95)$ & 0.130 & $0.983(0.343-2.817)$ & 0.974 \\
\hline \multicolumn{5}{|l|}{ Among those with $\mathrm{PP}<70$} \\
\hline ACEI-ARB + BB & $0.046(0.006-0.335)$ & 0.0023 & $0.74(0.178-3.085)$ & 0.6794 \\
\hline ACEI-ARB + No BB & $0.083(0.009-0.782)$ & 0.0296 & $0.07(0.01-0.477)$ & 0.0066 \\
\hline No ACEI-ARB + BB & $0.126(0.009-1.813)$ & 0.1280 & $0.867(0.152-4.954)$ & 0.8725 \\
\hline
\end{tabular}

*) compared to outcomes in patients without CAD; $\dagger$ ) compared to outcomes in patients with Glasgow Coma Scale $<9$; $\dagger \dagger$ ) compared to outcomes in patients not on ACEI or ARB or BB; Abbreviations: OR—odds ratio; IV—intravenous; HTN-hypertension; Rx—therapy; ACEI-angiotensin converting enzyme inhibitors; ARB—angiotensin receptor blockers; $\mathrm{BB}$ - beta blockers.

mortality was not influenced by choice of antihypertensive therapy (ACEI/ARB, $\mathrm{BB}$, both $\mathrm{ACEI} / \mathrm{ARB}$ and $\mathrm{BB}$, or neither $\mathrm{ACEI} / \mathrm{ARB}$ or $\mathrm{BB}$ ) in the $\mathrm{PP}>70$ group (Table 4). Among patients with PP $<70$, being on an ACEI/ARB based therapy without a BB was associated with a significantly lower follow-up mortality (OR $0.07,95 \%$ confidence interval $0.01-0.477, \mathrm{p}=0.0066$ ).

\section{Discussion}

In this retrospective cohort of patients admitted with a diagnosis of AIS, PP was not independently associated with short or long term mortality, but the use of an ACEI or ARB based antihypertensive regimen was associated with lower in-hospital among patients with $\mathrm{PP}<70$ or $\geq 70$. ACEI/ARB without $\mathrm{BB}$ was associated with lower follow-up mortality only those patients with baseline $\mathrm{PP}<70$.

A widened PP has been demonstrated in multiple analyses to be associated with a higher cardiovascular burden. Widened PP has been shown to correlate and associate with worse CV outcomes [31] [32]. The current analysis confirms that a widened PP is associated with increased mortality $(\mathrm{p}=0.020)$, however this did not persist when adjusted for multiple comorbidities. The only other analy- 
sis of PP on AIS outcomes demonstrated a significant association with weighted average PP (over 60 hours) on 3 month outcomes in the Glycine Antagonist in Neuroprotection International Trial; however, as with the current analysis, the baseline PP was not associated with follow-up outcomes after adjusting for comorbidities [7]. The association of average PP over the course of hospitalization with outcomes deserves further evaluation.

In contrast, choice of antihypertensive therapy remained significantly associated with outcomes with some notable differences based on baseline PP categorization. Regardless of baseline PP, being on an ACEI/ARB based antihypertensive therapy is associated with favorable in-hospital outcomes during AIS and including $\mathrm{BB}$ into the regimen attenuates the benefit. For long term mortality outcomes, ACEI/ARB based therapy was found to be beneficial in patients with $\mathrm{PP}<70$, with attenuation, again, from addition of $\mathrm{BB}$. There was a reduction in mortality with $\mathrm{ACEI} / \mathrm{ARB}$ based therapy, without $\mathrm{BB}$, among patients with $\mathrm{PP} \geq$ 70 however it did not meet statistical significance (OR 0.363, $\mathrm{p}=0.054)$.

The Scandinavian Candesartan Acute Stroke Trial (SCAST) randomized patients with acute stroke (the majority of whom, $\sim 85 \%$, had AIS) to initial treatment with Candesartan or placebo for hypertension management. This was not a BP target study and no data on PP was provided. The investigators found no significant difference in the primary outcome at 6 months or 3 years [33]. A direct comparison between a randomized study and a retrospective study is not possible however the current analysis may suggest that PP may be an important consideration when analyzing the effect of antihypertensive therapy on AIS outcomes.

$\mathrm{BB}$, on the other hand, were not associated with improved short and long term outcomes and attenuated some of the benefit seen with ACEI/ARB therapy. $\mathrm{BB}$ has been relegated to second line therapy in hypertension in general [27]. In regards to AIS, most of the data on BB therapy has been derived from retrospective studies. A recent analysis by Koton and colleagues looked at pre-stroke use of BB for hypertension management and post stroke outcomes [34]. These investigators found no effect on outcomes (stroke severity, recurrent stroke, or mortality) with the use of BB for pre-stroke hypertension therapy. Phelan and colleagues found a decrease in the in-hospital mortality in patients with AIS who had their home BB therapy continued during the first 3 days of AIS versus patients in whom BB therapy was discontinued [35]. This was despite a higher comorbid profile among patients on BB therapy [35]. Similarly, Tziomalos found worse in-hospital outcomes in patients treated with $\mathrm{BB}$ prior to AIS, than in those not treated with BB [36]. In contrast to our findings, Tziomalos and colleagues did not find a beneficial effect of ACEI or ARB therapy [36]. Similarly, Sykora and colleagues found improved in-hospital and 3-month AIS outcomes with the use of $\mathrm{BB}$ pre-stroke [37]. One important distinction from the current analysis is the duration of follow up; in our study, the duration of follow-up was significantly longer. In addition, distinctions in patient populations by PP have 
not been previously reported. Given the disparate findings among data sets, a well-designed randomized controlled trial examining the role of BB therapy in improving post stroke outcomes may be warranted.

Several important limitations of the current analysis need to be acknowledged. The choice of antihypertensive therapy was left to the discretion of the provider and thus introduces indication bias that cannot be adequately addressed in the current format. In addition, there is no means to know how patients were treated after the point of discharge. Addition or subtraction of hypertensive medications may have led to muted effects seen in the various subgroup analyses. Finally, our study contained modest sample size and follow up period as a larger sample size with longer follow up would be beneficial in studying this matter.

\section{Conclusion}

Despite these limitations, the current analysis revealed important distinctions within patients who have suffered AIS. ACEI/ARB based antihypertensive management appears to provide the most favorable short and long term outcomes in patients with AIS. This seems to be most prominent among patients with AIS and $P P<70$ at presentation. Future randomized controlled trials of patients with AIS should look at antihypertensive classes and PP interactions.

\section{References}

[1] Leonardi-Bee, J., Bath, P.M., Phillips, S.J., Sandercock, P.A. and Group ISTC (2002) Blood Pressure and Clinical Outcomes in the International Stroke Trial. Stroke, 33, 1315-1320. https://doi.org/10.1161/01.STR.0000014509.11540.66

[2] Jauch, E.C., Saver, J.L., Adams Jr., H.P., Bruno, A., Connors, J.J., Demaerschalk, B.M., Khatri, P., McMullan Jr., P.W., Qureshi, A.I., Rosenfield, K., Scott, P.A., Summers, D.R., Wang, D.Z., Wintermark, M., Yonas, H., American Heart Association Stroke Council, Council on Cardiovascular Nursing, Council on Peripheral Vascular Disease and Council on Clinical Cardiology (2013) Guidelines for the Early Management of Patients with Acute Ischemic Stroke: A Guideline for Healthcare Professionals from the American Heart Association/American Stroke Association. Stroke, 44, 870-947.https://doi.org/10.1161/STR.0b013e318284056a

[3] Zhao, R., Liu, F.D., Wang, S., Peng, J.L., Tao, X.X., Zheng, B., Zhang, Q.T., Yao, Q., Shen, X.L., Li, W.T., Zhao, Y., Liu, Y.S., Su, J.J., Shu, L., Zhang, M. and Liu, J.R. (2015) Blood Pressure Reduction in the Acute Phase of an Ischemic Stroke Does Not Improve Short- or Long-Term Dependency or Mortality: A Meta-Analysis of Current Literature. Medicine (Baltimore), 94, e896. https://doi.org/10.1097/MD.0000000000000896

[4] Vemmos, K.N., Tsivgoulis, G., Spengos, K., Zakopoulos, N., Synetos, A., Manios, E., Konstantopoulou, P. and Mavrikakis, M. (2004) U-Shaped Relationship between Mortality and Admission Blood Pressure in Patients with Acute Stroke. Journal of Internal Medicine, 255, 257-265. https://doi.org/10.1046/j.1365-2796.2003.01291.x

[5] Ahmed, N., Nasman, P. and Wahlgren, N.G. (2000) Effect of Intravenous Nimodipine on Blood Pressure and Outcome after Acute Stroke. Stroke, 31, 1250-1255. https://doi.org/10.1161/01.STR.31.6.1250

[6] White, W.B. (2002) Systolic versus Diastolic Blood Pressure versus Pulse Pressure. 
Current Cardiology Reports, 4, 463-467. https://doi.org/10.1007/s11886-002-0107-4

[7] Aslanyan, S., Weir, C.J. and Lees, K.R. (2004) Elevated Pulse Pressure during the Acute Period of Ischemic Stroke Is Associated with Poor Stroke Outcome. Stroke, 35, e153-e155. https://doi.org/10.1161/01.STR.0000126598.88662.16

[8] Blacher, J., Staessen, J.A., Girerd, X., Gasowski, J., Thijs, L., Liu, L., Wang, J.G., Fagard, R.H. and Safar, M.E. (2000) Pulse Pressure Not Mean Pressure Determines Cardiovascular Risk in Older Hypertensive Patients. Archives of Internal Medicine, 160, 1085-1089. https://doi.org/10.1001/archinte.160.8.1085

[9] Geeganage, C., Tracy, M., England, T., Sare, G., Moulin, T., Woimant, F., Christensen, H., De Deyn, P.P., Leys, D., O’Neill, D., Ringelstein, E.B. and Bath, P.M. (2011) Relationship between Baseline Blood Pressure Parameters (Including Mean Pressure, Pulse Pressure, and Variability) and Early Outcome after Stroke: Data from the Tinzaparin in Acute Ischaemic Stroke Trial (TAIST). Stroke, 42, 491-493. https://doi.org/10.1161/STROKEAHA.110.596163

[10] Ishitsuka, K., Kamouchi, M., Hata, J., Fukuda, K., Matsuo, R., Kuroda, J., Ago, T., Kuwashiro, T., Sugimori, H., Nakane, H. and Kitazono, T. (2014) High Blood Pressure after Acute Ischemic Stroke Is Associated with Poor Clinical Outcomes: Fukuoka Stroke Registry. Hypertension, 63, 54-60. https://doi.org/10.1161/HYPERTENSIONAHA.113.02189

[11] Tomii, Y., Toyoda, K., Suzuki, R., Naganuma, M., Fujinami, J., Yokota, C. and Minematsu, K. (2011) Effects of 24-Hour Blood Pressure and Heart Rate Recorded with Ambulatory Blood Pressure Monitoring on Recovery from Acute Ischemic Stroke. Stroke, 42, 3511-3517. https://doi.org/10.1161/STROKEAHA.111.628586

[12] Geeganage, C. and Bath, P.M. (2010) Vasoactive Drugs for Acute Stroke. The Cochrane Database of Systematic Reviews, No. 7, CD002839. https://doi.org/10.1002/14651858.CD002839.pub2

[13] Chapman, N., Huxley, R., Anderson, C., Bousser, M.G., Chalmers, J., Colman, S., Davis, S., Donnan, G., MacMahon, S., Neal, B., Warlow, C., Woodward, M. and Writing Committee for the PCG (2004) Effects of a Perindopril-Based Blood Pressure-Lowering Regimen on the Risk of Recurrent Stroke According to Stroke Subtype and Medical History: The PROGRESS Trial. Stroke, 35, 116-121. https://doi.org/10.1161/01.STR.0000106480.76217.6F

[14] Hassan, Y., Aziz, N.A., Al-Jabi, S.W., Looi, I. and Zyoud, S.H. (2010) Impact of Angiotensin-Converting Enzyme Inhibitors Administration Prior to Acute Ischemic Stroke Onset on In-Hospital Mortality. Journal of Cardiovascular Pharmacology and Therapeutics, 15, 274-281. https://doi.org/10.1177/1074248410373751

[15] Zuliani, G., Cherubini, A., Volpato, S., Atti, A.R., Ble, A., Vavalle, C., Di Todaro, F., Benedetti, C., Ruggiero, C., Senin, U. and Fellin, R. (2005) Treatment with Angiotensin-Converting Enzyme Inhibitors Is Associated with a Reduction in Short-Term Mortality in Older Patients with Acute Ischemic Stroke. The Journals of Gerontology. Series A, Biological Sciences and Medical Sciences, 60, 463-465. https://doi.org/10.1093/gerona/60.4.463

[16] Schrader, J., Luders, S., Kulschewski, A., Berger, J., Zidek, W., Treib, J., Einhaupl, K., Diener, H.C., Dominiak, P. and Acute Candesartan Cilexetil Therapy in Stroke Survivors Study G (2003) The ACCESS Study: Evaluation of Acute Candesartan Cilexetil Therapy in Stroke Survivors. Stroke, 34, 1699-1703. https://doi.org/10.1161/01.STR.0000075777.18006.89

[17] Sandset, E.C., Bath, P.M., Boysen, G., Jatuzis, D., Korv, J., Luders, S., Murray, G.D., Richter, P.S., Roine, R.O., Terent, A., Thijs, V., Berge, E. and Group, S.S. (2011) The Angiotensin-Receptor Blocker Candesartan for Treatment of Acute Stroke (SCAST): 
A Randomised, Placebo-Controlled, Double-Blind Trial. The Lancet, 377, 741-750.

[18] Bath, P.M., Martin, R.H., Palesch, Y., Cotton, D., Yusuf, S., Sacco, R., Diener, H.C., Toni, D., Estol, C., Roberts, R. and Group, P.R.S. (2009) Effect of Telmisartan on Functional Outcome, Recurrence, and Blood Pressure in Patients with Acute Mild Ischemic Stroke: A Profess Subgroup Analysis. Stroke, 40, 3541-3546.

https://doi.org/10.1161/STROKEAHA.109.555623

[19] Lattanzi, S., Silvestrini, M. and Provinciali, L. (2013) Elevated Blood Pressure in the Acute Phase of Stroke and the Role of Angiotensin Receptor Blockers. International Journal of Hypertension, 2013, Article ID: 941783. https://doi.org/10.1155/2013/941783

[20] Horn, J. and Limburg, M. (2001) Calcium Antagonists for Ischemic Stroke: A Systematic Review. Stroke, 32, 570-576. https://doi.org/10.1161/01.STR.32.2.570

[21] Potter, J.F., Robinson, T.G., Ford, G.A., Mistri, A., James, M., Chernova, J. and Jagger, C. (2009) Controlling Hypertension and Hypotension Immediately Post-Stroke (CHHIPS): A Randomised, Placebo-Controlled, Double-Blind Pilot Trial. The Lancet Neurology, 8, 48-56.

[22] Barer, D.H., Cruickshank, J.M., Ebrahim, S.B. and Mitchell, J.R. (1988) Low Dose Beta Blockade in Acute Stroke ("BEST" Trial): An Evaluation. British Medical Journal, 296, 737-741. https://doi.org/10.1136/bmj.296.6624.737

[23] Rashid, P., Leonardi-Bee, J. and Bath, P. (2003) Blood Pressure Reduction and Secondary Prevention of Stroke and Other Vascular Events: A Systematic Review. Stroke, 34, 2741-2748. https://doi.org/10.1161/01.STR.0000092488.40085.15

[24] Alberts, M.J., Hademenos, G., Latchaw, R.E., Jagoda, A., Marler, J.R., Mayberg, M.R., Starke, R.D., Todd, H.W., Viste, K.M., Girgus, M., Shephard, T., Emr, M., Shwayder, P. and Walker, M.D. (2000) Recommendations for the Establishment of Primary Stroke Centers. Brain Attack Coalition. JAMA, 283, 3102-3109. https://doi.org/10.1001/jama.283.23.3102

[25] Adams, H.P., Adams, R.J., Brott, T., del Zoppo, G.J., Furlan, A., Goldstein, L.B., Grubb, R.L., Higashida, R., Kidwell, C., Kwiatkowski, T.G., Marler, J.R., Hademenos, G.J. and Stroke Council of the American Stroke A (2003) Guidelines for the Early Management of Patients with Ischemic Stroke: A Scientific Statement from the Stroke Council of the American Stroke Association. Stroke, 34, 1056-1083. https://doi.org/10.1161/01.STR.0000064841.47697.22

[26] Schwamm, L.H., Fonarow, G.C., Reeves, M.J., Pan, W., Frankel, M.R., Smith, E.E., Ellrodt, G., Cannon, C.P., Liang, L., Peterson, E. and Labresh, K.A. (2009) Get with the Guidelines-Stroke Is Associated with Sustained Improvement in Care for Patients Hospitalized with Acute Stroke or Transient Ischemic Attack. Circulation, 119, 107-115. https://doi.org/10.1161/CIRCULATIONAHA.108.783688

[27] James, P.A., Oparil, S., Carter, B.L., Cushman, W.C., Dennison-Himmelfarb, C., Handler, J., Lackland, D.T., LeFevre, M.L., MacKenzie, T.D., Ogedegbe, O., Smith, S.C., Svetkey, L.P., Taler, S.J., Townsend, R.R., Wright, J.T., Narva, A.S. and Ortiz, E. (2014) 2014 Evidence-Based Guideline for the Management of High Blood Pressure in Adults: Report from the Panel Members Appointed to the Eighth Joint $\mathrm{Na}$ tional Committee (JNC 8). JAMA, 311, 507-520. https://doi.org/10.1001/jama.2013.284427

[28] Lenfant, C., Chobanian, A.V., Jones, D.W., Roccella, E.J., Joint National Committee on the Prevention DE and Treatment of High Blood P (2003) Seventh Report of the Joint National Committee on the Prevention, Detection, Evaluation, and Treatment of High Blood Pressure (JNC 7): Resetting the Hypertension Sails. Hypertension, 41, 1178-1179. https://doi.org/10.1161/01.HYP.0000075790.33892.AE 
[29] Curb, J.D., Ford, C.E., Pressel, S., Palmer, M., Babcock, C. and Hawkins, C.M. (1985) Ascertainment of Vital Status through the National Death Index and the Social Security Administration. American Journal of Epidemiology, 121, 754-766. https://doi.org/10.1093/aje/121.5.754

[30] Fillenbaum, G.G., Burchett, B.M. and Blazer, D.G. (2009) Identifying a National Death Index Match. American Journal of Epidemiology, 170, 515-518. https://doi.org/10.1093/aje/kwp155

[31] Asmar, R., Safar, M. and Queneau, P. (2003) Pulse Pressure: An Important Tool in Cardiovascular Pharmacology and Therapeutics. Drugs, 63, 927-932. https://doi.org/10.2165/00003495-200363100-00001

[32] Kuvin, J.T., Sidhu, M., Patel, A.R., Sliney, K.A., Pandian, N.G. and Karas, R.H. (2005) Pulse Pressure and Peripheral Arterial Vasoreactivity. Journal of Human Hypertension, 19, 501-502. https://doi.org/10.1038/sj.jhh.1001844

[33] Hornslien, A.G., Sandset, E.C., Igland, J., Terent, A., Boysen, G., Bath, P.M., Murray, G.D. and Berge, E. (2015) Effects of Candesartan in Acute Stroke on Vascular Events during Long-Term Follow-Up: Results from the Scandinavian Candesartan Acute Stroke Trial (SCAST). International Journal of Stroke, 10, 830-835. https://doi.org/10.1111/ijs.12477

[34] Koton, S., Tanne, D. and Grossman, E. (2017) Prestroke Treatment with Beta-Blockers for Hypertension Is Not Associated with Severity and Poor Outcome in Patients with Ischemic Stroke: Data from a National Stroke Registry. Journal of Hypertension, 35, 870-876. https://doi.org/10.1097/HJH.0000000000001218

[35] Phelan, C., Alaigh, V., Fortunato, G., Staff, I. and Sansing, L. (2015) Effect of Beta-Adrenergic Antagonists on In-Hospital Mortality after Ischemic Stroke. Journal of Stroke and Cerebrovascular Diseases, 24, 1998-2004.

[36] Tziomalos, K., Giampatzis, V., Bouziana, S.D., Spanou, M., Papadopoulou, M., Kazantzidou, P., Kostaki, S., Kouparanis, A., Savopoulos, C. and Hatzitolios, A.I. (2015) Effects of Different Classes of Antihypertensive Agents on the Outcome of Acute Ischemic Stroke. The Journal of Clinical Hypertension (Greenwich), 17, 275-280. https://doi.org/10.1111/jch.12498

[37] Sykora, M., Siarnik, P., Diedler, J. and Collaborators, V.A. (2015) Beta-Blockers, Pneumonia, and Outcome after Ischemic Stroke: Evidence from Virtual International Stroke Trials Archive. Stroke, 46, 1269-1274.

https://doi.org/10.1161/STROKEAHA.114.008260 